\title{
O uso do Canabidiol no Brasil e o posicionamento do Órgão Regulador
}

\author{
The use of Cannabidiol in Brazil and positioning of the National Regulator Organ \\ El uso del cannabidiol en Brasil y el posicionamiento de la Junta Nacional Reguladora
}

\section{Leandro Arantes de Melo' Alethele de Oliveira Santos ${ }^{2}$}

RESUMO: O artigo apresenta a posição dos estudiosos do canabidiol, acerca de seu uso terapêutico, bem como analisa o posicionamento do Órgão Regulador Nacional, a Agência Nacional de Vigilância Sanitária (Anvisa) e os acórdãos do Tribunal de Justiça do Estado de São Paulo (TJSP) e o Tribunal Regional Federal da $3^{\underline{a}}$ Região (TRF3a), acerca do fornecimento de tal substância no Brasil, nos anos 2014 e 2015. Foi realizada pesquisa exploratória do uso do canabidiol para fins clínicos, de normativas da Anvisa que tratem sobre o tema; e de acórdãos no banco de dados do TJSP e TRF3a. Os achados revelaram que estudos e decisões judiciais guardaram relação quanto aos fundamentos e que o órgão regulador apresentou, no tempo estudado, alteração de posicionamento.

Palavras-chave: Direito à Saúde. Assistência Farmacêutica. Canabidiol. Direito Sanitário.

ABSTRACT: This article presents the position of the cannabidiol the scholars about its therapeutic use as well as analyzes the positioning National Regulator Organ, the National Health Surveillance Agency (Anvisa) and the judgments of the Court of the State of São Paulo (TJSP) and the Federal Regional Court of the 3rd Region (TRF3a) concerning the provision of such substance in Brazil, during the years 2014 and 2015. An exploratory study of cannabidiol use for clinical purposes, Anvisa's normative and the judgments in the database of TJSP and TRF3a that deals on the subject was performed. The findings revealed that studies and court decisions that bear relation to the fundamentals that the regulator organ presented in the studied time to change its position.

Keywords: Right to Health. Pharmaceutical Services. Cannabidiol. Health Law.

RESUMEN: En este artículo se presenta la posición de los estudiosos acerca del uso terapéutico del cannabidiol y analiza el posicionamiento de la Junta Nacional Reguladora, la Agencia Nacional de Vigilancia Sanitaria (Anvisa) y las sentencias del Tribunal del Estado de São Paulo (TJSP) y el Tribunal Regional Federal de la 3a Región (TRF3a) relativo a la concesión de la sustancia en Brasil, en los años 2014 y 2015. Se realizó la investigación exploratoria del uso de cannabidiol con fines clínicos, de acuerdo con los reglamentos de la Anvisa y resoluciones judiciales en la base de datos del TJSP y TRF3a. Los resultados revelaron que los estudios y las decisiones de los tribunales estaban relacionados con fundamentos que la Junta Nacional Reguladora presentó, en este periodo, para cambiar su posición.

Palabras-Ilave: Derecho a la Salud. Servicios Farmacêuticos. Cannabidiol. Derecho Sanitario.

\footnotetext{
${ }^{1}$ Consultor técnico do Ministério da Saúde. Secretaria de Atenção à Saúde. Brasília - Distrito Federal. Brasil. E-mail: leandroarantes87@gmail.com

2 Doutoranda em Saúde Coletiva pela Universidade de Brasília (Unb). Advogada, Assessora Técnica do Conselho Nacional de Secretários de Saúde (Conass). Distrito Federal - Brasil. Email: alethele@ig.com.br
} 


\section{Introdução}

A cannabis sativa, popularmente conhecida no Brasil como maconha ou cânhamo, teve seu primeiro uso documentado como medicamento por volta de 2300 a.C., quando o chinês Chen Nong prescreveu a chu-ma (cânhamo fêmea) para o tratamento de gota, constipação, malária, reumatismo e problemas menstruais e a classificou como um dos "supremos elixires da imortalidade" (1).

A cannabis sativa é uma planta complexa, com vários canabinoides presentes em sua composição, sendo cada um deles com um efeito diferente, e ainda, com a possibilidade de que alguns alteram o efeito de outros. A título de exemplo, o canabidiol (CBD), que é uma substância presente na cannabis sativa, segundo estudos, é considerado livre de efeitos psicotrópicos, redutor da ansiedade, provoca sensação de bem-estar generalizado e contribui na concentração. Além de ser eficaz como medicamento (2), o CBD reduz os efeitos do tetra-hidrocanabinol (THC) (3).

É preciso que o leitor saiba que há um movimento chamado Medicina Baseada em Evidências e que tem contribuído para a discussão sobre a teoria e a prática da medicina, onde se inclui o uso clínico das substâncias da cannabis sativa. Esse movimento busca melhorar a qualidade da assistência médica, onde a experiência clínica se integra com a capacidade de análise crítica para aplicar a informação científica de forma racional (4). O Centro Cochrane do Brasil é considerado uma das referências acerca de Medicina Baseada em Evidências no país (5).

No Brasil, para que substâncias possam ser usadas como medicamento, além de estudos que atestem sua capacidade clínica, as mesmas devem estar devidamente registradas. Por meio da Lei oㅜ6.360/1976 (6), já se exigia em território nacional o registro de medicamentos, antes mesmo da existência da Agência Nacional de Vigilância Sanitária (Anvisa), que foi criada a partir da Lei no 9.782/1999 (7), que Ihe conferiu competência para regulamentar, controlar e fiscalizar os produtos e serviços que envolvam risco à saúde pública, dentre esses produtos e serviços, o medicamento. Logo, qualquer manifestação deste órgão regulador acerca do assunto é importante.

Ultrapassados os trâmites de registro nacional, os medicamentos, para que sejam utilizados no âmbito do Sistema Único de Saúde (SUS), devem integrar à Relação Nacional de Medicamentos Essenciais (RENAME) (8), cuja revisão foi estabelecida como uma das diretrizes da Política Nacional de Medicamentos, regulamentada pela Portaria 
GM/MS 3.916, de 30 de outubro de 1998 (9). Os medicamentos a serem dispensados pelo SUS são submetidos à análise prévia da Comissão Nacional de Incorporação de Tecnologias do SUS (CONTEC), conforme a Lei ㄲo 12.401, de 28 de abril de 2011 (10).

O contexto revela que em face da Constituição Federal de 1988, em seu artigo 196, afirmar que a saúde é um direito de todos e dever do estado (11) e a busca pela prestação positiva em saúde tem levado brasileiros aos tribunais de justiça, quer sejam usuários do sistema público ou privado de saúde, de modo a obter autorização judicial para a importação do CBD, para fins medicinais.

Considerada a escassez de material sobre o CBD e seu uso medicinal no Brasil, o presente artigo apresenta o posicionamento de alguns estudiosos sobre o assunto, do Órgão Regulador de medicamentos no Brasil, a Anvisa, e a análise de acórdãos proferidos pelo Tribunal de Justiça do Estado de São Paulo (TJSP), bem como, Tribunal Regional Federal da $3^{\underline{a}}$ Região (TRF3a). No decorrer da apresentação de dados são evidenciados debates que o assunto suscita acerca da exigência de registro para medicamentos (6) (7).

\section{Metodologia}

Foi realizado estudo exploratório (12) sobre a utilização da substância Canabidiol (CBD), derivada da Cannabis Sativa, para fins clínicos, em território brasileiro.

O estudo exploratório é um procedimento metodológico de abordagem qualitativa, que possibilita conhecer a variável apresentada, seu significado e o contexto onde ela se insere. Permite que a realidade seja apropriada como ela é, refina os dados, corrige vieses, aumenta o grau de objetividade e pode levar à criação de um instrumento de pesquisa condizente à realidade (12).

Primeiramente foram pesquisados autores que refiram o uso da substância em finalidade clínica e suas restrições, no território brasileiro, nos anos de 2014 e 2015 . Foi utilizada a base de dados do Google Acadêmico, a partir dos descritores agrupados: "canabidiol", "cannabis sativa", "medicina" e "saúde". A busca retornou 19 arquivos relacionados aos descritores. Para a seleção do material utilizado na pesquisa, foi realizada leitura flutuante, que requer do pesquisador o contato intenso com o material de campo. (13)

A partir do contato com o material, houve a exclusão de alguns arquivos, por não apresentarem conexão com a temática tratada, como é o caso de Pinto (2015) e 
Nascimento (2014) ou por não haver, arquivos integralmente acessíveis para dounload ou leitura, o que se aplica a Pernoncini, (2014), Matos Gonçalves (2014), Sugasti (2014), Burgierman (2011) e Borges (2015). Houve ainda a exclusão de um arquivo em repetição, que é o caso de Dinis-Oliveira (2014).

Os 11 arquivos restantes corresponderam aos critérios de inclusão: (i) disponibilidade de arquivo; (ii) adequação aos objetivos da pesquisa; (iii) presença dos descritores selecionados; (iv) publicação em língua portuguesa, e são eles: Wessler (2014); Bastos (2015); Ribeiro (2014); Bueno (2015); Nascimento (2014); Silvano (2014); Malcher-Lopes (2014); Balbino (2014); Reis (2014); Dinis-Oliveira (2014); e Mantovani (2014).

$\mathrm{Na}$ base de dados da Biblioteca Virtual em Saúde (BVS), que compila os bancos: LILACS, IBECS, MEDLINE, SciELO e Biblioteca Cochrane (essa última deixou de integrar a base de dados da BVS em 16/12/2015), foram feitos os mesmos procedimentos de busca, a partir da utilização dos descritores agrupados, nos anos de 2014 e 2015. Para a base de dados BVS é preciso salientar que a busca com descritores isolados permite achados, todavia, para essa pesquisa interessou somente os termos agrupados, que associa o CBD ao seu uso medicinal. Assim considerando, a BVS não apresentou nenhum arquivo a ser estudado.

Os procedimentos de busca, a partir de descritores agrupados, também foram aplicados ao sítio oficial da Comissão Nacional de Incorporação de Tecnologias no Sistema Único de Saúde (Conitec), não resultando em nenhum achado.

Em segundo momento, foi pesquisada a posição do órgão regulador nacional, a Agência Nacional de Vigilância Sanitária (Anvisa), acerca da utilização clínica do CBD, a partir de seu sítio oficial. Foram identificadas normativas que tratam do assunto, a fim de possibilitar uma descrição cronológica, do ocorrido nos anos de 2014 e 2015.

$\mathrm{Na}$ finalização de captação de material de pesquisa, foram analisados os acórdãos ${ }^{3}$ (14), do Tribunal de Justiça do Estado de São Paulo (TJSP) e Tribunal Regional Federal da 3a Região (TRF3a), nos anos de 2014 e 2015, acerca de pleitos pelo uso medicinal do CBD, a partir do uso dos mesmos descritores utilizados para as bases anteriormente consultadas, todavia - utilizados conjuntamente, não retornaram resultados.

Assim, optou-se por utilizar os descritores: "canabidiol", "medicamento" e "saúde", de forma agrupada, nas bases de dados disponibilizadas pelos respectivos tribunais em seus

\footnotetext{
${ }^{3}$ Julgamentos proferidos pelos tribunais, conforme artigo 163 do Código de Processo Civil.
} 
respectivos portais eletrônicos (15) (16). É importante salientar a possibilidade de que haja processos em segredo de justiça, e que por não comporem a base de dados pesquisada, não foram considerados.

Explica-se que no Brasil, a Justiça Federal é composta por Juízes Federais que atuam em primeira instância e Tribunais Regionais Federais (segunda instância), além dos Juizados Especiais Federais, podendo figurar como parte processual a União (11), no âmbito da pesquisa representada pelo TRF3a, que inclui o estado de São Paulo. A Justiça Estadual é composta por Juízes de Direito (primeira instância) e pelos Desembargadores (segunda instância), cabendo julgar conforme a Constituição de cada estado, e figuram como parte os estados ou municípios (11) e refere, para o estudo, o TJSP. A escolha pelos tribunais do estado de São Paulo, com decisões em âmbito recursal, se deu pelo fato de tratar-se do estado mais populoso do país, correspondendo a $21,7 \%$ da população nacional (17).

Foram encontrados sete acórdãos no TJSP, dos quais um foi descartado, por se tratar de matéria alheia ao objeto da pesquisa. Os demais acórdãos foram considerados para a pesquisa por tratarem da temática relacionada ao uso clínico do CBD, pretendido judicialmente. Quais sejam: (i) Agravo 2028403-23.2015.8.26.0000/50000; (ii) Embargos de Declaração 2028403-23.2015.8.26.0000/50001; (iii) Agravo 205397833.2015.8.26.0000; (iv) Agravo de Instrumento 2086356-42.2015.8.26.0000; (v) Agravo 2136255-09.2015.8.26.0000; e (vi) Agravo 2135642-86.2015.8.26.0000. A busca no sítio oficial do TRF3a não apresentou resultados para os anos 2014 e 2015, entretanto, deve-se salientar a possibilidade de que haja processo em segredo de justiça.

Todas as bases de dados utilizadas são de acesso livre e desembaraçado, constituindo fonte secundária de pesquisa.

Para a fundamentação dos debates, foram utilizados como material auxiliar capítulos de livros, publicações, normativa de conselho de classe, todas devidamente identificadas no decorrer do texto.

\section{RESULTADOS E DISCUSSÃO}

Para além de outros debates que refiram a descriminalização do uso da maconha em território brasileiro, a discussão que se faz nesse estudo refere o uso do canabidiol para fins medicinais, com fundamento na premissa de que é o CBD representa $40 \%$ dos 
canabinóides presentes na cannabis sativa, e é livre de efeitos alucinógenos, ou seja, não possui efeitos psicotrópicos (18).

Para apresentação didática dos resultados encontrados foi elaborada o Quadro I, que identifica os autores e o conteúdo de suas publicações, possibilitando agrupamento de informações para o debate.

\section{Quadro I - Identificação de autoria e conteúdo dos artigos identificados}

\begin{tabular}{|c|c|c|c|}
\hline Ano & Título & Autor & Conteúdo \\
\hline 2014 & $\begin{array}{l}\text { Efeitos Neuroquímicos e } \\
\text { Comportamentais causados pelo uso } \\
\text { da Cannabis Sativa }\end{array}$ & $\begin{array}{l}\text { Bruna Giassi } \\
\text { Wessler }\end{array}$ & $\begin{array}{l}\text { Estudo bibliográfico acerca do uso da cannabis } \\
\text { sativa, descrição das propriedades físico-químicas. } \\
\text { Afirma que o canabidiol é um composto que não } \\
\text { possui efeitos psicoativos. }\end{array}$ \\
\hline 2015 & $\begin{array}{l}\text { Política de drogas na segunda } \\
\text { década do novo milênio: reforma ou } \\
\text { revolução }\end{array}$ & $\begin{array}{l}\text { Francisco } \\
\text { Inácio } \\
\text { Bastos }\end{array}$ & $\begin{array}{l}\text { Debate acerca da política de drogas. Afirma que o } \\
\text { canabidiol não possui efeitos psicoativos, e que o } \\
\text { Conselho Federal de Medicina referendou o uso de } \\
\text { canabidiol para tratamento da epilepsia refratária. }\end{array}$ \\
\hline 2014 & $\begin{array}{l}\text { A Cannabis e suas aplicações } \\
\text { terapêuticas }\end{array}$ & $\begin{array}{l}\text { José António } \\
\text { Curral } \\
\text { Ribeiro }\end{array}$ & $\begin{array}{l}\text { Estudo das aplicações terapêuticas da cannabis } \\
\text { sativa, afirmou que o THC possui efeito } \\
\text { psicotrópico, sem indicar o mesmo sobre o } \\
\text { canabidiol, e estudos sobre e o mecanismo de } \\
\text { ação dos canabinóides de forma geral. }\end{array}$ \\
\hline 2014 & $\begin{array}{l}\text { A Concretização do Direito à Saúde } \\
\text { pelo Poder Judiciário: O caso de } \\
\text { Anny Fischer }\end{array}$ & $\begin{array}{l}\text { Fernanda } \\
\text { Silva Bueno }\end{array}$ & $\begin{array}{l}\text { Fez a análise de um caso ocorrido no Distrito } \\
\text { Federal e foi capaz de demonstrar que, ao } \\
\text { contrário do THC, o canabidiol não possui efeito } \\
\text { psicotrópico. Fez ainda a análise da concretização } \\
\text { do acesso ao direito à saúde através do Poder } \\
\text { Judiciário. }\end{array}$ \\
\hline 2014 & $\begin{array}{l}\text { Identificação Química em Nível } \\
\text { Molecular de Amostras de Maconha } \\
\text { por ESI-FT-ICR MS }\end{array}$ & $\begin{array}{l}\text { lendel Rubio } \\
\text { do } \\
\text { Nascimento }\end{array}$ & $\begin{array}{l}\text { Identificação química em nível molecular de } \\
\text { amostras de cannabis sativa, reafirmando que o } \\
\text { THC possui efeito psicotrópico, contudo, sem } \\
\text { mencionar se o canabidiol possui os mesmos } \\
\text { efeitos. }\end{array}$ \\
\hline 2014 & $\begin{array}{l}\text { Da possibilidade da } \\
\text { descriminalização e da legalização } \\
\text { da Maconha no Brasil e suas } \\
\text { consequências }\end{array}$ & $\begin{array}{l}\text { Marciele } \\
\text { Silvano }\end{array}$ & $\begin{array}{l}\text { Aborda o tema de descriminalização da cannabis } \\
\text { sativa e afirma que o canabidiol não possui efeitos } \\
\text { psicotrópicos. }\end{array}$ \\
\hline 2014 & $\begin{array}{l}\text { Canabinoides ajudam a desvendar } \\
\text { aspectos etiológicos em comum e } \\
\text { trazem esperança para o tratamento } \\
\text { de autismo e epilepsia }\end{array}$ & $\begin{array}{l}\text { Renato } \\
\text { Malcher- } \\
\text { Lopes }\end{array}$ & $\begin{array}{l}\text { Afirma que o canabidiol não possui efeito } \\
\text { psicotrópico, e ainda enfatiza que os canabinoides } \\
\text { podem auxiliar no tratamento de epilepsia e } \\
\text { evidencia os elos etiológicos entre epilepsia e } \\
\text { transtornos do espectro do autismo. }\end{array}$ \\
\hline 2014 & $\begin{array}{l}\text { Estudo do comportamento } \\
\text { eletroquímico do } \Delta 9 \text { - } \\
\text { tetraidrocanabinol derivatizado com } \\
\text { Fast Blue } B\end{array}$ & $\begin{array}{l}\text { Marco } \\
\text { Antonio } \\
\text { Balbino }\end{array}$ & $\begin{array}{l}\text { Estudo da composição química da cannabis sativa. } \\
\text { Informa que o canabidiol deixou de ser substância } \\
\text { proscrita (proibida) para se tornar substância } \\
\text { prescrita. }\end{array}$ \\
\hline 2014 & $\begin{array}{l}\text { Caminhoneiras e Drogas - } \\
\text { Desconstruindo a Resolução } 460 \text { do } \\
\text { Conselho Nacional de Trânsito }\end{array}$ & $\begin{array}{l}\text { Arthur } \\
\text { Amaral Reis }\end{array}$ & $\begin{array}{l}\text { Estudo da Resolução } 460 \text { do Conselho Nacional de } \\
\text { trânsito e seus impactos na classe de } \\
\text { caminhoneiros. Traça um breve histórico da } \\
\text { cannabis sativa e mencionou a criação de um } \\
\text { "mercado negro" no tocante ao acesso do } \\
\text { canabidiol. }\end{array}$ \\
\hline
\end{tabular}




\begin{tabular}{|l|l|l|l|}
\hline \hline 2014 & Uso Lícito e llícito dos Fármacos & $\begin{array}{l}\text { Ricardo } \\
\text { Jorge Dinis- } \\
\text { Oliveira }\end{array}$ & $\begin{array}{l}\text { Discute a farmodinâmica de algumas substâncias } \\
\text { psicoativas. Afirma que são 61 canabinoides, das } \\
400 \text { compostos docuementados presentes na } \\
\text { cannabis sativa, e que o canabidiol não tem efeito } \\
\text { psicoativo. }\end{array}$ \\
\hline 2014 & $\begin{array}{l}\text { Uso da extração acelerada por } \\
\text { colvente (ASE) para determinação } \\
\text { cromatográfica de analitos de } \\
\text { cocaína e tetraidrocanabinol em } \\
\text { amostras de mecônio }\end{array}$ & $\begin{array}{l}\text { Cínthia de } \\
\text { Carvalho } \\
\text { Mantovani } \\
\text { aplicação para identificar os biomarcadores da } \\
\text { exposição fetal à cocaína e tetraidrocanabinol em } \\
\text { amostras de mecônio. Menciona que o canabidiol é } \\
\text { quantativamente um dos mais importantes } \\
\text { canabinoides presentes na cannabis sativa. }\end{array}$ \\
\hline
\end{tabular}

Fonte: elaboração do $1^{\circ}$ autor com base nas fontes citadas para a pesquisa.

Em termos gerais, dos artigos estudados, afere-se que a declaração da ausência de efeitos psicotrópicos do CBD é majoritária, que há destaque para os efeitos benignos nos tratamentos da epilepsia e evidencia os elos etiológicos entre epilepsia e transtornos do espectro do autismo. Essas afirmativas decorrem das expressões de Wessler (19); Bastos (20); Bueno (18); Nascimento (21); Silvano (22); Dinis-Oliveira (23) e Malcher-Lopes (24). Ribeiro (25), Balbino (26); Reis (27); e Mantovani (28) foram inespecíficos quanto à ausência de efeitos psicotrópicos do CBD.

Cumpre apresentar que, apesar de o CBD ser cientificamente considerado adequado para tratamento de epilepsia, até o ano de 2014 era considerada substância proscrita pela Anvisa, isto é, substância cujo uso está proibido no Brasil, presente na "Lista F" da Portaria da Secretaria de Vigilância em Saúde do Ministério da Saúde (SVS/MS) № 344/1998 (29), impedindo assim, a importação do CBD, o que fez com que os interessados em adquirir a substância, a solicitassem administrativamente ou ainda, ao Poder Judiciário (30).

Face ao contexto social que exigiu, por solicitações administrativas ou por decisões judiciais, posicionamento acerca do CBD, o Conselho Federal de Medicina (CFM), órgão que fiscaliza e normatiza a prática médica no Brasil (31), por meio da Resolução CFM no 2.113/2014 (32), aprovou o uso do canabidiol para o tratamento de epilepsias da criança e do adolescente. Da mesma forma, até o dia 03 de dezembro de 2014, a Anvisa havia recebido 297 pedidos de importação do CBD, dos quais autorizou 238 solicitações, 17 aguardavam cumprimento de exigências pelos interessados e 34 estavam sob análise técnica (30).

A Resolução de Diretoria Colegiada (RDC) n 17, de 06 de maio de 2015 (33), que decorre de discussão interna da Diretoria Colegiada (34) - ato administrativo próprio da Anvisa -, indicou que o CBD passou a ser considerada substância controlada, presente na 
"Lista C1" da Portaria SVS/MS no 344/1998 (29), ainda que não haja registro do CBD como medicamento, conforme exigido na Lei no 6.360/1976 (6), na Lei no 9.782/1999 (7) e no Decreto no 8.077/2013 (35). Há que se crer que os movimentos sociais, as solicitações administrativas e judiciais, as decisões judiciais e a posição do CFM, contribuíram para a alteração do posicionamento do órgão regulador em face do CBD.

Observados os acórdãos do TJSP, pode-se afirmar que no decorrer do tempo estudado, as decisões beneficiaram aos solicitantes do CBD, em detrimento das proibições existentes.

Quadro 2 - Acórdãos sobre CBD exarados pelo TJSP, 2014-2015

\begin{tabular}{|c|c|c|c|c|}
\hline Ano & Tribunal & Processo & Relator & Resumo \\
\hline 2015 & TJSP & $\begin{array}{l}\text { AGRAVO } \\
\text { 2028403- } \\
23.2015 .8 .26 .0000 / 50000\end{array}$ & $\begin{array}{l}\text { Teresa } \\
\text { Ramos } \\
\text { Marques }\end{array}$ & $\begin{array}{l}\text { Decisão a favor de conceder o fornecimento do medicamento } \\
\text { canabidiol para tratamento de convulsão. Decidiu-se com base na } \\
\text { reclassificação pela Anvisa como medicamento de uso controlado, e } \\
\text { que o registro do medicamento não foi efetuado no Brasil devido à } \\
\text { necessidade de transcorrer o processo administrativo. }\end{array}$ \\
\hline 2015 & TJSP & $\begin{array}{l}\text { EMBARGOS DE } \\
\text { DECLARAÇÃO } \\
\text { 2028403- } \\
23.2015 .8 .26 .0000 / 50001\end{array}$ & $\begin{array}{l}\text { Teresa } \\
\text { Ramos } \\
\text { Marques }\end{array}$ & $\begin{array}{l}\text { Decisão a favor de conceder o fornecimento do medicamento } \\
\text { canabidiol para tratamento de convulsão. Decidiu-se com base na } \\
\text { reclassificação pela Anvisa como medicamento de uso controlado, e } \\
\text { que o registro do medicamento não foi efetuado no Brasil devido à } \\
\text { necessidade de transcorrer o processo administrativo. }\end{array}$ \\
\hline 2015 & TJSP & $\begin{array}{l}\text { AGRAVO } \\
\text { 2053978- } \\
33.2015 .8 .26 .0000\end{array}$ & $\begin{array}{l}\text { Egidio } \\
\text { Giacoia }\end{array}$ & $\begin{array}{l}\text { Decisão a favor de conceder o fornecimento do medicamento } \\
\text { canabidiol para tratamento para crise epiléptica. Decidiu-se com base } \\
\text { na prescrição médica e no risco de dano irreparável ou de difícil } \\
\text { reparação à vida. }\end{array}$ \\
\hline 2015 & TJSP & $\begin{array}{l}\text { AGRAVO } \\
\text { 2086356- } \\
42.2015 .8 .26 .0000\end{array}$ & $\begin{array}{l}\text { Moreira } \\
\text { de } \\
\text { Carvalho }\end{array}$ & $\begin{array}{l}\text { Decisão a favor de conceder o fornecimento do medicamento } \\
\text { canabidiol para tratamento de convulsão. Decidiu-se com base na } \\
\text { reclassificação pela Anvisa como medicamento de uso controlado, e } \\
\text { que o registro do medicamento não foi efetuado no Brasil devido à } \\
\text { necessidade de transcorrer o processo administrativo, além de existir } \\
\text { prescrição médica. }\end{array}$ \\
\hline 2015 & TJSP & $\begin{array}{l}\text { AGRAVO } \\
2136255- \\
09.2015 .8 .26 .0000\end{array}$ & $\begin{array}{l}\text { Marcia } \\
\text { Dalla } \\
\text { Déa } \\
\text { Barone }\end{array}$ & $\begin{array}{l}\text { Decisão a favor de conceder o fornecimento do medicamento } \\
\text { canabidiol para tratamento para crise epiléptica. Decidiu-se com base } \\
\text { na prescrição médica e no risco de dano irreparável ou de difícil } \\
\text { reparação à vida. }\end{array}$ \\
\hline 2015 & TJSP & $\begin{array}{l}\text { AGRAVO } \\
2135642- \\
86.2015 .8 .26 .0000\end{array}$ & $\begin{array}{l}\text { Reinaldo } \\
\text { Miluzzi }\end{array}$ & $\begin{array}{l}\text { Decisão a favor de conceder o fornecimento do medicamento } \\
\text { canabidiol para tratamento de convilsão, negando o recurso } \\
\text { de parte do Estado. Decidiu-se com base no risco de dano } \\
\text { irreparável ou de difícil reparação à vida. }\end{array}$ \\
\hline
\end{tabular}

Fonte: TJSP

Dos dados apresentados no quadro II, observa-se que os diversos relatores mantêm a posição de que o CBD deve ser concedido (importação autorizada) em favor do solicitante. 
Também se extrai da leitura das referidas decisões que não houve menção aos estudos clínicos existentes sobre o assunto e que os fundamentos referem, principalmente, a prescrição médica e o risco de dano irreparável ou de difícil reparação à vida.

\section{Considerações finais}

A pesquisa apresenta posicionamento, nos anos 2014 e 2015, da produção científica, do órgão regulador e do Tribunal de Justiça do Estado de São Paulo. Algumas observações são relevantes: (i) do tempo estudado, houve alteração de posicionamento do órgão regulador, na medida em que exclui o CBD da lista de substâncias proibidas e o insere naquela de substâncias que podem ser prescritas; (ii) não há menção, quer nos artigos científicos, quer nos atos administrativos regulatórios, acerca da judicialização da substâncias CBD; (iii) segundo os artigos pesquisados, o CBD não possui efeitos psicotrópicos e pode apresentar bons resultados clínicos, especialmente no tratamento da epilepsia.

Há várias questões que indicam a necessidade de estudos mais detalhados, em âmbito nacional, que sejam capazes de apresentar e analisar decisões monocráticas e recursais, da justiça estadual e federal, acerca do CBD, em todo o território nacional. Essa avaliação pode ser ilustrada pela ponderação de que, mesmo sendo a Anvisa, órgão regulador federal, o TRF3a não apresentou resultados na pesquisa, o que fez buscar a exploração a decisões em âmbito estadual e suscitando dúvidas acerca da presença da União nas lides que referem o CBD em território brasileiro.

Da mesma forma, ampliando-se o tempo pesquisado e garantindo-se amostra nacional, pode ser avaliada a importância dada pelos magistrados ao registro de medicamentos nacional, às normativas do órgão regulador e às teses, comumente discutidas no âmbito da judicialização, como a obrigação do Estado Brasileiro em fornecer medicamento sem registro, ou experimental, ou em uso fora de bula.

Esse estudo exploratório permitiu constatar que a produção científica sobre o CBD no Brasil ainda é recente e deve ser expandida, a partir da formulação de projeto de pesquisa mais abrangente, com lapso temporal que permita verificar os cenários que antecedem e sucedem as alterações normativas (CFM e Anvisa) ocorridas nos anos 2014 e 2015 e aqui apresentadas e que seja capaz de colaborar com os tomadores de decisão, na medida em que poderá ofertar, informação nova, atual e não evidente. 


\section{Referências}

1 Robinson R. O Grande Livro da Cannabis: Guia completo de seu uso industrial, medicinal e ambiental. Rio de Janeiro: Jorge Zahar Editor; 1999.

2 Borges LQ. Proteja sua família das drogas. Jundiaí: Paco Editorial; 2015.

3 Burgierman DR. O fim da guerra: a maconha e a criação de um novo sistema para lidar com as drogas. São Paulo: Leya; 2011.

4 Lopes AA. Medicina Baseada em Evidências: a arte de aplicar o conhecimento científico na prática clínica. Revista da Associação Médica Brasileira. 2000, 46(3): 285-8 Disponível em: https://repositorio.ufba.br/ri/bitstream/ri/2863/1/3089.pdf [Acesso em 08 nov 2015].

5 Centro Cochrane do Brasil. Saúde baseada em evidências. São Paulo.. Disponível em: http://www.centrocochranedobrasil.org .br/cms/index.php?option=com content\& view=article \&id=4\&ltemid=13 [Acesso em 16 dez 2015]

6 Brasil. Lei nº 6.360, de 23 de setembro de 1976. Dispõe sobre a Vigilância Sanitária a que ficam sujeitos os Medicamentos, as Drogas, os Insumos Farmacêuticos e Correlatos, Cosméticos, Saneantes e Outros Produtos, e dá outras Providências. Brasília, 24 set 1976 Disponível em: http://www.planalto.gov.br/ccivil 03/leis/l6360.htm [Acesso em 07 nov 2015].

7 Lei no 9.782, de 26 de janeiro de 1999. Define o Sistema Nacional de Vigilância Sanitária, cria a Agência Nacional de Vigilância Sanitária, e dá outras providências [Internet]. Brasilia, 27 jan 1999 Disponível em: http://www.planalto.gov.br/ccivil 03/leis/L9782.htm [Acesso em 07 nov 2015].

8 _. Ministério da Saúde. Relação Nacional dos Medicamentos Essenciais: RENAME 2014. 9 ed. rev. e atual. Brasília: Ministério da Saúde; 2015. Disponível em: http://bvsms.saude.gov.br/bvs/publicacoes/relacao nacional medicamentos essenciais re name 2014.pdf [Acesso em 15 nov 2015]

9 Ministério da Saúde. Portaria no 3.916, de 30 de outubro de 1998. Aprova a Política Nacional de Medicamentos. Brasília, 10 nov 1998 Disponível em: http://bvsms.saude.gov.br/bvs/saudelegis/gm/1998/prt3916 $30 \quad 10$ 1998.html [Acesso em 15 nov 2015].

10 . Lei no 12.401, de 29 de abril de 2011. Altera a Lei no 8.080, de 19 de setembro de 1990 , para dispor sobre a assistência terapêutica e a incorporação de tecnologia em saúde no âmbito do Sistema Único de Saúde - SUS. Brasilia, 29 abr 2011 Disponível em: http://www.planalto.gov.br/ccivil 03/ Ato2011-2014/2011/Lei/L12401.htm [Acesso em 15 nov 2015].

11 . Constituição da República Federativa do Brasil, de 05 de outubro de 1988. Brasília, 05 out 1988 Disponível em: http://www.planalto.gov.br/ccivil 03/Constituicao/Constituicao.htm [Acesso em 08 nov 2015]. 
12 Piosevan A, Temporini ER. Pesquisa exploratória: procedimento metodológico para o estudo de fatores humanos no campo da saúde pública. Revista Saúde Pública 29(4): 318 25,1995 Disponível em: http://www.scielo.br/pdf/rsp/v29n4/10 .[Acesso em 07 nov 2015].

13 Minayo MCS. O Desafio do Conhecimento: Pesquisa Qualitativa em Saúde. 10 ed. São Paulo: Hucitec; 2007.

14 Brasil. Lei no 5.869, de 11 de janeiro de 1973. Institui o Código de Processo Civil. Brasília, 17 jan 1973]. Disponível em:

http://www.planalto.gov.br/ccivil 03/leis/L5869compilada.htm [Acesso em 15 nov 2015

15 . Tribunal de Justiça do Estado de São Paulo. Consulta de jurisprudência. São Paulo, 2015. [Acesso em 08 nov 2015]. Disponível em:

https://esaj.tjsp.jus.br/cjsg/consultaCompleta.do?f=1

16 . Tribunal Regional Federal da 3 $3^{\underline{a}}$ Região. Pesquisa Temática de Jurisprudência. São Paulo, 2015. Disponível em:

http://www.trf3.jus.br/NXT/Gateway.dll? f=templates\&fn=default.htm\&vid=trf3e:trf3ve [Acesso em 08 nov 2015].

17 . Instituto Brasileiro de Geografia e Estatística. [Nota Técnica]. Estimativas da população dos municípios brasileiros com data de referência em $1^{\circ}$ de julho de 2014. Brasilia: IBGE, 2014. Disponível em:

http://www.ibge.gov.br/home/presidencia/noticias/pdf/analise estimativas 2014.pdf [Acesso em 15 nov 2015].

18 Bueno FS. A Concretização do Direito à Saúde pelo Poder Judiciário: o caso de Anny Fischer [Monografia]. Brasilia: Graduação em Direito, Centro Universitário UniCEUB; 2014. Disponível em: http://repositorio.uniceub.br/bitstream/235/6135/1/21171188.pdf [Acesso em 30 out 2015].

19 Wessler BG. Efeitos Neuroquímicos e Comportamentais causados pelo uso da Cannabis Sativa [Monografia]. Criciúma: Pós-Graduação em Farmacologia, Universidade do Extremo Sul Catarinense; 2014. Disponível em: http://repositorio.unesc.net/handle/1/2388 [Acesso em 09 nov 2015].

20 Bastos FI. Política de drogas na segunda década do novo milênio: reforma ou revolução. Argumentum, v.7, n.1, p.8-16, jan/jun, 2015 Disponível em:

http://periodicos.ufes.br/argumentum/article/view/9873/7242 [Acesso em 09 nov 2015].

21 Nascimento IR. Identificação Química em Nível Molecular de Amostras de Maconha por ESI-FT-ICR MS [Dissertação]. Espírito Santo: Programa de Pós-Graduação em Química, Universidade Federal do Espírito Santo; 2014. Disponível em:

http://repositorio.ufes.br/bitstream/10/1233/1/Dissertacao\%20 ldentifica\%C3\%A7\%C3\%A3o \%20Qu\%C3\%ADmica\%20em\%20N\%C3\%ADvel\%20Molecular\%20de\%20Amostras\%20de \%20de\%20Maconha\%20por\%20ESI-FT-ICR\%20MS.pdf [Acesso em 30 out 2015]

22 Silvano M. Da Possibilidade da Descriminalização e da Legalização da Maconha no Brasil e suas consequências [Monografia]. Santa Catarina: Programa de Graduação em 
Direito, Universidade do Extremo Sul Catarinense; 2014. Disponível em: http://200.18.15.27/bitstream/1/2748/1/Marciele\%20Silvano.pdf [Acesso em 30 out 2015].

23 Dinis-Oliviera RJ. Usos Lícito e llícito dos Fármacos. Acta Médica Portuguesa 27(6): 755-766, 2014. Disponível em:

http://www.actamedicaportuguesa.com/revista/index.php/amp/article/view/5215/4146 [Acesso em 09 nov 2015]

24 Malcher-Lopes R. Canabinoides ajudam a desvendar aspectos etiológicos em comum e trazem esperança para o tratamento de autismo e epilepsia. Revista da Biologia, 13(1): 43-59, 2014 Disponível em: http://www.ib.usp.br/revista/system/files/07 Malcher-Lopes.pdf [Acesso em 30 out 2015].

25 Ribeiro JAC. A Cannabis e suas aplicações terapêuticas [Monografia]. Porto, Portugal: Programa de Mestrado em Ciências Farmacêuticas, Universidade Fernando Pessoa; 2014. Disponível em: http://bdigital.ufp.pt/bitstream/10284/4828/1/PPG 20204.pdf [Acesso em 30 out 2015].

26 Balbino MA. Estudo do comportamento eletroquímico do $\Delta^{9}$-tetraidrocanabinol derivatizado com Fast Blue B [Tese]. Ribeirão Preto: Programa de Pós-Graduação em Química, Universidade de São Paulo; 2014. Disponível em: http://www.teses.usp.br/teses/disponiveis/59/59138/tde-01122014231252/publico/versaofinalteseMarcoBalbino.pdf [Acesso em 30 out 2015].

27 Reis AA. Caminhoneiros e drogas: desconstruindo a Resolução 460 do Conselho Nacional de Trânsito [Monografia]. Porto Alegre: Programa de Graduação em Direito, Universidade Federal do Rio Grande do Sul; 2014. Disponível em: http://www.lume.ufrgs.br/handle/10183/112039 [Acesso em 30 out 2015].

28 Mantovani CC. Uso da extração acelerada por solvente (ASE) para determinação cromatográfica de analitos de cocaína e tetraidrocanabinol em amostras de mecônio [Dissertação]. São Paulo: Programa de Pós-Graduação em Toxicologia e Análise Toxicológicas, Universidade de São Paulo; 2014. Disponível em: http://www.teses.usp.br/teses/disponiveis/9/9141/tde-15072014-160904/en.php [Acesso em 09 nov 2015].

29 Brasil. Ministério da Saúde. Portaria no 344 de 12 de maio de 1998. A prova o Regulamento Técnico sobre substâncias e medicamentos sujeitos a controle especial. Diário Oficial da União. Brasília, 15 mai 1998. Disponível em:

http://bvsms.saude.gov.br/bvs/saudelegis/svs/1998/prt0344 12051998 rep.htm I[Acesso em 29 out 2015].

30 Agência Nacional de Vigilância Sanitária. Sobe para 297 o número de pedidos de importação de Canabidiol recebidos. Brasilia, 2014. Disponível em: http://s.anvisa.gov.br/wps/s/r/cWX3 [Acesso em 20 outubro 2015].

31 Conselho Federal de Medicina. A instituição. Brasilia, 2010 [22 jul 2010]. Disponível em: http://portal.cfm.org.br/index.php?option=com content\& view=article\&id=20671\&ltemid=23 [Acesso em 15 nov 2015]. 
32 Conselho Federal de Medicina. Resolução CFM no 2.113/2014, de 30 de outubro de 2014. Aprova o uso compassivo do canabidiol para o tratamento de epilepsias da criança e do adolescente refratárias aos tratamentos convencionais. Diário Oficial da União. Brasília, 16 dez 2014.]. Disponível em:

http://pesquisa.in.gov.br/imprensa/jsp/visualiza/index.jsp?jornal=1\&pagina=183\&data=16/1 2/2014 [Acesso em 08 nov 2015

33 Brasil. Agência Nacional de Vigilância Sanitária. RDC nํ17 de 06 de maio de 2015. Define os critérios e os procedimentos para a importação, em caráter de excepcionalidade, de produto à base de Canabidiol em associação com outros canabinóides, por pessoa física, para uso próprio, mediante prescrição de profissional legalmente habilitado, para tratamento de saúde. Diário Oficial da União. Brasília 08 mai 2015. Disponível em:

http://pesquisa.in.gov.br/imprensa/jsp/visualiza/index.jsp?data=08/05/2015\&jornal=1\&pagin

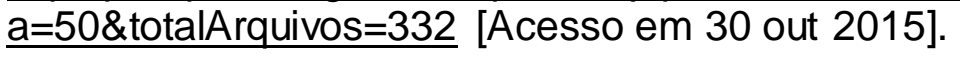

34 . Agência Nacional de Vigilância Sanitária. Diretoria Colegiada. Brasilia, 2009. Disponível em:

http://portal.anvisa.gov.br/wps/content/Anvisa+Portal/Anvisa/Agencia/Assunto+de+Interess e/Diretoria+Colegiada [Acesso em 15 nov 2015].

35 . Decreto no 8.077, de 14 de agosto de 2015. Regulamenta as condições para o funcionamento de empresas sujeitas ao licenciamento sanitário, e o registro, controle e monitoramento, no âmbito da vigilância sanitária, dos produtos de que trata a Lei no 6.360, de 23 de setembro de 1976, e dá outras providências. Brasília, 14 ago 2013 Disponível em: http://www.planalto.gov.br/ccivil 03/ Ato2011-2014/2013/Decreto/D8077.htm [Acesso em 30 out 2015].

\section{Como citar este artigo:}

Melo LA, Santos AO. O uso do Canabidiol no Brasil e o posicionamento do Órgão Regulador. Revista Cadernos Ibero-Americanos de Direito Sanitário. 2016 abr./jun, 5(2):43-56. 